\title{
O milagre da juventude: uma análise linguística de exemplares de discurso publicitário da indústria antienvelhecimento ${ }^{1}$
}

\author{
Sílvia Barbosa*, Mariana Silva Ninitas ${ }^{* *}$ \\ ${ }^{*}$ NOVA/FCSH CLUNL, * Universidade Aberta
}

\begin{abstract}
In this work, we aim to analyze how the cosmetic industry communicates the idea of aging and how it offers solutions for reversing this natural process, in the advertising speeches about face creams, aimed at the female audience. We built a corpus of 112 texts on cosmetic products, collected in beauty catalogs, websites of beauty brands and retail chains in the perfumery and cosmetics market, which have a set of texts in European Portuguese on the theme of "aging". From a perspective of Lexical-Semantic analysis with contributions of the Discourse Analysis Pragmatics we tried to identify linguistic patterns to understand which discursive strategies were manipulated when advertising products promise to reverse the natural aging process. We observed that brands have products where the name is not always self-explanatory of the function it proposes and without great commitment to the possible solution, as aging and the respective physical marks are understood as the result of a process that the skin suffered and not the person.
\end{abstract}

Keywords: Face Threatening Acts, ethos; ageing, beauty brands, advertising

Palavras-chave: envelhecimento, cosmética, discurso publicitário

\section{Introdução}

O presente trabalho tem como principal objetivo analisar o modo como a indústria cosmética comunica a ideia de envelhecimento e como oferece soluções de reversão deste processo natural, nomeadamente em discursos publicitários sobre cremes de rosto, óleos e séruns, direcionados ao público feminino.

Pretende-se, por um lado, analisar a forma como a indústria da cosmética comunica com o consumidor a ideia de envelhecimento, o que lhe diz sobre o que é envelhecer e de que forma apresenta soluções para reverter/desacelerar/atenuar esse processo natural. Ademais, o presente trabalho tem, igualmente, o intuito de identificar quais as estratégias discursivas e as escolhas lexicais utilizadas nos discursos publicitários, em particular aqueles que são dirigidos ao público feminino, aquando da apresentação de cremes de rosto.

Para a prossecução dos objetivos gerais acima elencados, apresentaremos informações relativas a uma amostra de textos (texto breve/curto do produto que é publicitado) relativa a 112 produtos da nossa Base de Dados.

\section{Comunicar o Envelhecimento}

A indústria cosmética está presente na vida de todos com maior ou menor peso, seja através de artigos de higiene pessoal, pela perfumaria, pela cosmética ou outros. É, como facilmente se compreenderá, uma indústria

\footnotetext{
${ }^{1}$ Este trabalho foi financiado por fundos nacionais através da FCT - Fundação para a Ciência e Tecnologia, I.P., - como parte do projeto CLUNL, Faculdade de Ciências Sociais e Humanas, Universidade NOVA de Lisboa, 1069-061 Lisboa, Portugal (UIDB/LIN/03213/2020 e UIDP/LIN/03213/2020).
} 
milionária com um valor de negócios de cerca de 60 mil milhões de euros (dados relativos ao ano de 2019²) e com tendência para aumentar.

Segundo Palacios (2004), existem duas visões principais relativas à velhice: uma mais cristalizada, que impõe a imagem de que o envelhecimento é uma "época sombria, decrépita, repleta de temores de morte, de acometimentos de doenças, que culminam com o isolamento do indivíduo dos processos de socialização" (p. 2), e outra que, segundo a mesma autora, aponta para a existência de uma terceira idade e, consequentemente, remete para a imagem de "sucessibilidade, ou seja, [para] a existência de fases anteriores: a primeira e a segunda idades" (p. 4). Assim, a primeira idade diria respeito à infância, a segunda à maturidade e a terceira a uma fase posterior que, embora possa ser entendida como final, dissipa a ideia de decrepitude e deixa em aberto a possibilidade de existirem outras fases posteriores, como a quarta ou a quinta idades.

Segundo Blaikie (apud Weirnick, 2000), a criação da expressão "terceira idade" surge com o período pósmoderno, que, pelo aumento da esperança média de vida e a diminuição da natalidade (e da fecundidade), permite atenuar a ideia de fragilidade dos grupos etários mais velhos, convertendo a imagem a eles associada num conjunto de novas características: a velhice passa, assim, a ser sinónimo de força, atividade, bem-estar, lazer, autodesenvolvimento. Bruckner (1997) sugere, assim, que a idade deixa de ser um veredito.

É, por isso, natural que a publicidade tenha acompanhado a tendência das transformações demográficas acima mencionadas, bem como das práticas de consumo que surgiram como sua consequência. Riou (1999) refere que as novas tendências publicitárias são o reflexo das transformações sociais, reforçando-as. Cathelat (2001), por outro lado, alerta para o facto de a margem de ação da publicidade ser frágil, ainda que possa ser considerada um "motor cultural" (p. 177), pela possibilidade de inovação que, muitas vezes, excede os limites de tolerância do público-alvo e, a nosso ver, transforma o desconforto causado numa necessidade de consumo.

Segundo Castro (2004, p. 18), a esfera de consumo sobrepõe-se, maioritariamente, à esfera de produção. A autora acredita que a sociedade e os seus indivíduos definem a sua identidade pelas escolhas que fazem, estabelecendo, desta forma, distinções sociais e estilos de vida diferenciados. A publicidade, nesta sequência, e segundo a mesma autora, entrega esse poder de escolha ao seu consumidor por meio do seu produto e do estilo de vida que a ele se associa. Desta forma, e seguindo Soulanges (1996), o processo de construção da mensagem publicitária segue as tendências de consumo, mas também as inova.

O discurso publicitário, a par da imagem e de outros elementos cruciais, representa um dos pontos mais importantes para que a mensagem pretendida chegue ao interlocutor de forma clara.

Adam e Bonhomme (1997) afirmam que uma das características mais relevantes da estrutura global do discurso publicitário é a de adaptar a mensagem ao público-alvo e, através de pré-construídos socioculturais, transformá-lo no seu coenunciador. Assim, e ainda que, muitas vezes, conforme expresso acima, a publicidade crie algum desconforto ao seu público, o discurso publicitário procura não beliscar o ethos ou a face do seu coenunciador, recorrendo ao politicamente correto para evitar Face Threatening Acts (FTAs) (Goffman, 1979).

Segundo Volkoff (2004), o chamado "politicamente correto" não foi inventado por ninguém, mas sim consequência da decadência do espírito crítico da sociedade. Desta forma, o discurso publicitário procura evitar termos que possam constranger o seu público ao ponto de o repelir.

De facto, o discurso publicitário, para ser bem conseguido, permite construir ou reforçar a identidade do seu público, integrando-o num determinado paradigma social. Fairclough (2001), retomando Foucault, relembra que a forma como um indivíduo usa a linguagem afeta a sua identidade, da mesma forma que a recetividade do interlocutor a determinado discurso define o círculo social em que este se quer inserir.

Evidentemente, e conforme brevemente abordado acima, a publicidade acompanha a evolução da sociedade. Assim, quando há uma transformação social, a publicidade torna-se reflexo da mesma, ajudando a construir uma mensagem que, no caso dos textos em estudo, apela ao consumo e pretende mitigar ou reconstruir

2 Informação disponível em Associação Portuguesa de Estudantes de Farmácia, acedida em 26 de outubro de 2020 em https://apef.pt/industria-cosmetica-posp. 
a imagem trazida por essas mudanças - o que é bastante evidente no caso dos produtos antienvelhecimento. Desta forma, cria um ciclo, mas também acompanha o consumidor. Evidencia ou cria necessidades e, ao mesmo tempo, na tentativa de chegar a um público mais abrangente, ajuda-o a posicionar-se perante a marca ou o produto. Perante a dúvida sobre se determinado produto é adequado, a publicidade auxilia o potencial consumidor, recorrendo a diversas estratégias, das quais se destacam o texto e a imagem. Vejamos, abaixo, um exemplo do funcionamento da publicidade, no que aos produtos cosméticos diz respeito.

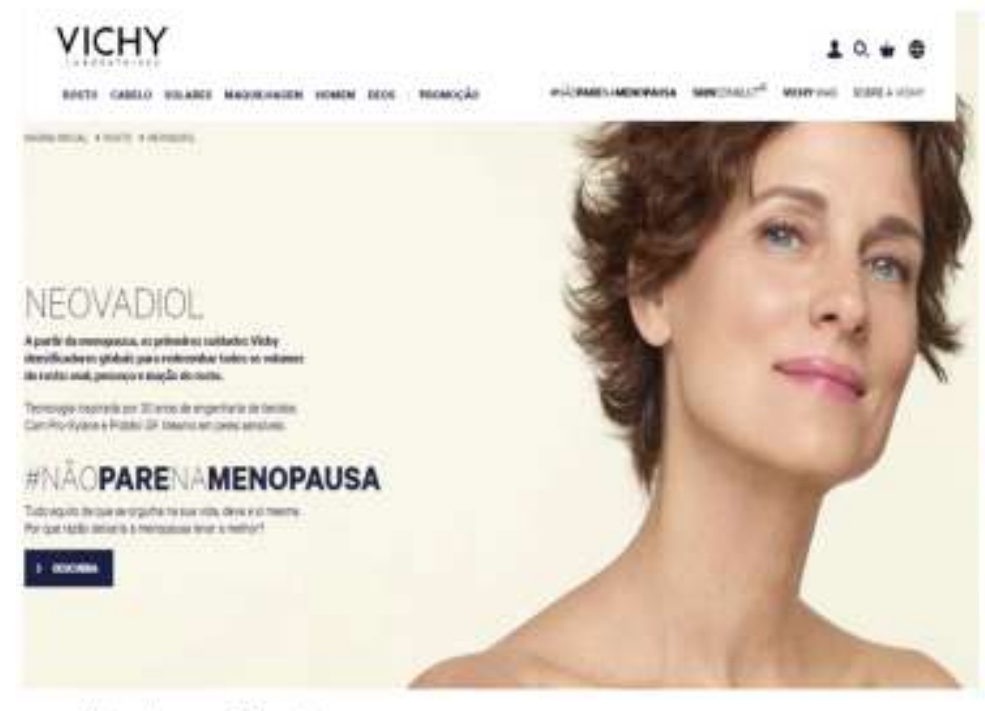

https://www.vichy.pt

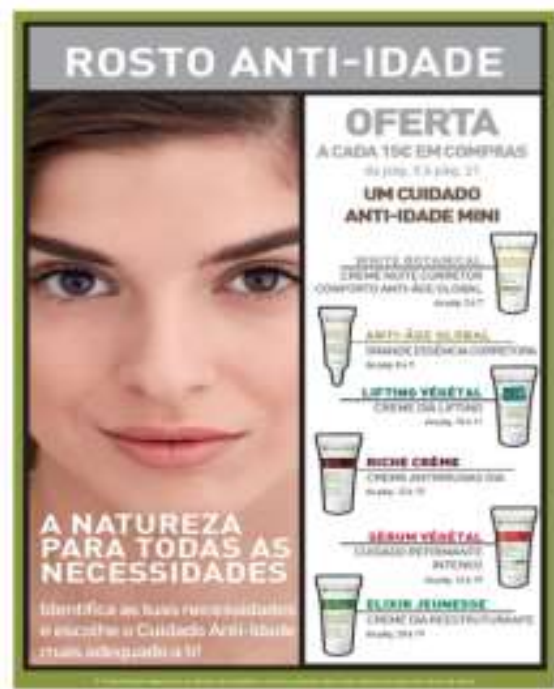

bttps://catalogos.yvesrocher.pt/2020/catalogo-14/

Figura 1. Exemplos de publicidade de produtos cosméticos.

$\mathrm{Na}$ imagem apresentada à esquerda ${ }^{3}$ na Figura 1, a marca (Vichy) opta por apresentar uma etiqueta "menopausa" - como forma de marcar o tempo e fazer com que, facilmente, um grupo de consumidores se identifique com o produto, sentindo-se, desta forma, impelido a comprá-lo. O discurso publicitário é breve e não oferece soluções específicas para a pele, mas para a vida - "\#NÃOPARENAMENOPAUSA".

$\mathrm{Na}$ imagem da direita ${ }^{4}$ na Figura 1, por outro lado, verificamos que a marca (Yves Rocher) procura conduzir o potencial consumidor à identificação de um "problema" ou de uma necessidade, através da apresentação simultânea do problema e da solução. Neste caso, a marca elenca, através da apresentação de um conjunto de produtos e das suas características, diferentes soluções para problemas que o leitor só saberá diagnosticar quando perante a descrição do produto.

Em ambos os casos, e na sequência do que Adam e Bonhome (1997), por exemplo, referem, a publicidade tem de ir ao encontro das necessidades do seu coenunciador, sem o antagonizar. Por essa razão, o discurso publicitário só deverá ser desconfortável ao ponto de levar o seu consumidor a acreditar que tem determinada

\footnotetext{
${ }^{3}$ Para efeitos de legibilidade transcrevemos o texto: "NEOVADIOL - A partir da menopausa, os primeiros cuidados Vichy densificadores globais para redesenhar todos os volumes do rosto: oval, pescoço e maçãs do rosto. Tecnologia inspirada por 30 anos de engenharia de tecidos. Com Pro-Xylane e Protéic GF. Mesmo em peles sensíveis. \#NÃOPARENAMENOPAUSA Tudo aquilo de que se orgulha na sua vida, deve a si mesma. Por que razão deixaria a menopausa levar a melhor?"

${ }^{4}$ Para efeitos de legibilidade transcrevemos o texto: "Rosto Anti-Idade - A natureza para todas as necessidades. Identifica as tuas necessidades e escolhe o Cuidado Anti-idade mais adequado a ti!"
} 
necessidade, mas não ao ponto de violentar a sua face, depois desse diagnóstico. Por essa razão, o discurso tem de levar o seu consumidor a acreditar numa melhoria, construindo, desta forma, uma imagem de sonho que se enquadre no que o consumidor quer ser e não naquilo que ele acredita ser no momento da compra. Nessa medida, nas imagens anteriores, vemos mulheres com um ar bem-disposto e aparentemente saudável, características que poderão ser invejadas e desejadas. A este propósito, importa referir que não é nosso objetivo refletir com maior profundidade sobre a evidente falta de representatividade de mulheres não-caucasianas, uma vez que foge ao escopo do trabalho. Ainda assim, desafiamos o leitor a refletir sobre esse tema.

\section{Metodologia e Perspetivas de Análise}

Para a prossecução dos objetivos acima identificados, a investigação que se apresenta segue uma metodologia mista (qualitativa e quantitativa) e enquadra-se numa perspetiva de análise Léxico-Semântica, ainda que convoque, sempre que necessário, contributos da Pragmática e da Análise do Discurso.

Considerando que um discurso publicitário, conforme creem Adam e Bonhomme (1997) - qualquer que seja o género em que se insira - cria um coenunciador, ou seja, é, em si mesmo, uma prática dialogal (in absentia), serão convocados os contributos das teorias interacionais de Kerbrat-Orecchioni (1980, 1992, 2001, 2005, entre outros), bem como das teorias de argumentação no discurso numa perspetiva retórica (Amossy, 1999, 2012), nomeadamente a noção de ethos. Amossy acredita que o ethos é a construção da imagem do enunciador no discurso, sendo a eficácia do discurso dependente da imagem social de que se reveste o enunciador e da construção discursiva no quadro interacional, perspetiva relevante na análise que propomos.

Ainda contemplando a noção de construção da imagem do locutor/alocutário, convocaremos a noção de face, proposta por Goffman (1967). Segundo o autor, o termo face designa a imagem que o interlocutor tem de si mesmo e que é construída a partir de atributos socialmente aceites (Goffman, 1967, p. 5). Goffman (1967, p. 7) acredita, igualmente, que todos os participantes têm noção da quantidade de possibilidades de que dispõem numa determinada interação, tendo em conta a natureza convencionalizada da mesma e a imagem que pretendem construir de si mesmos. A face de um interveniente do discurso mantém-se enquanto condição e não tanto como objetivo da interação (Goffman, 1967, p. 12). Dentre as inúmeras formas de proteger a face dos intervenientes, crê-se que as mais frequentes sejam evitar um dado tema ou o processo de correção. $\mathrm{O}$ não cumprimento - muitas vezes intencional - dos princípios de proteção da face geram os chamados FTAs.

Vion (2000) refere que o recurso ao implícito permite, por vezes, mitigar algum potencial ataque à face do outro, preservando-a. Neste sentido, também essa noção será por nós convocada. Segundo Fonseca (1992), o poder do discurso não se esgota na palavra explícita, antes, sim, prolonga-se e amplia-se, por via da codificação do implícito (Fonseca, 1992, p. 368). Grice, na sua obra Logic and Conversation (1975), evidencia a diferença entre a significação da frase e o sentido do enunciado. Na mesma linha, Duarte (2005) afirma que "o falante comunica quase sempre mais do que aquilo que diz e, às vezes, comunica diferente daquilo que diz" (p. 291), o que, na senda do defendido por Grice (1975), implica que o interlocutor recorra a processos de inferência para interpretar esses mesmos enunciados e os seus implícitos (agregados ao dito ou à enunciação). Ademais, "a interpretação de um enunciado faz apelo a um conjunto de premissas, sendo algumas de natureza cultural” (Mauai, 2015, p. 121). É, pois, no valor ilocutório (derivado e/ou implicitado) que o locutor calcula, enquanto «ser do mundo» (Ducrot, 1980; Marques, 2000) e a partir do seu conhecimento enciclopédico (Kerbrat-Orechionni, 1986), o significado dos diferentes atos de fala.

No presente trabalho, foi elaborada uma pesquisa com o intuito de compreender que marcas de cosméticos existem e são vendidas em Portugal, algumas em nome próprio como a NIVEA, outras em catálogos de beleza como a ORIFLAME (que só vendem a sua própria marca), cadeias de retalho no mercado da perfumaria e cosmética com lojas físicas em Portugal (DOUGLAS) e websites de marcas de beleza como a SKIN (que possuem um repositório de diversas marcas). 
O milagre da juventude: uma análise linguística de exemplares de discurso publicitário da indústria antienvelhecimento

A SKIN, por ser uma plataforma com uma maior diversidade de produtos (ao nível dos preços e ao nível das marcas) e também por ser um dos sites mais pesquisados em Portugal, acabou por ser a plataforma escolhida para selecionarmos os produtos pretendidos e construir a Base de Dados (BD) que é constituída por 112 exemplares de discurso publicitário, escritos em português europeu e cujo tema é o envelhecimento, associado a produtos cosméticos, extraídos entre janeiro e setembro de 2020 do respetivo website .

A BD foi construída com a informação organizada da seguinte forma: o nome do produto, a capacidade (em ml), o preço, a tipologia, e o texto da descrição do produto (este texto caracteriza-se por ser conciso, incidindo sobre o produto que é publicitado, escrito normalmente pela própria marca que o vende e comercializa). A título de exemplo, veja-se a Figura 2.

\begin{tabular}{|c|c|c|c|c|c|}
\hline$N .^{o}$ & produto & capacidade & preço & tipologia & descriçãa $o^{5}$ \\
\hline 73 & $\begin{array}{c}\text { L'Oréal Revitalift Laser X3 } \\
\text { Creme De Dia Intensivo Anti- } \\
\text { Idade }\end{array}$ & 50 & 27,29 & 1_barato & $\begin{array}{l}\text { L'Oréal Revitalift Laser X3 Creme de Dia é um creme anti- } \\
\text { idade, de tripla ação, que corrige as rugas e principais sinais de } \\
\text { envelhecimento, enquanto melhora a firmeza e redefine os } \\
\text { contornos do rosto. Hidrata profundamente. Atua nas rugas, } \\
\text { alisando e suavizante. De efeito lifting, estimula e melhora as } \\
\text { fibras de sustentação da pele. Redensifica a pele e redefine os } \\
\text { contornos do rosto. Reduz visivelmente as manchas da pele. } \\
\text { Ideal para peles maduras e envelhecidas. }\end{array}$ \\
\hline 54 & $\begin{array}{l}\text { Frezyderm Botulin Effect } \\
\text { Creme Anti-rugas }\end{array}$ & 50 & 56,37 & 2_acessível & $\begin{array}{l}\text { Frezyderm Botulin Effect Creme é um creme anti- } \\
\text { envelhecimento global, que hidrata intensamente, enquanto } \\
\text { corrige as rugas visíveis na zona da testa, contorno dos olhos, } \\
\text { da boca e do nariz. Com um efeito relaxante (tipo botox), alisa } \\
\text { intensamente, aumenta a densidade e preenche as linhas e } \\
\text { rugas. Hidrata e nutre profundamente. Protege contra as } \\
\text { agressões externas diárias. Pode ser usado após tratamentos } \\
\text { cosméticos para melhores resultados. Ideal para todo o tipo de } \\
\text { pele, com rugas. Dermatologicamente testado. }\end{array}$ \\
\hline 41 & $\begin{array}{c}\text { Esthederm Intensive Retinol } \\
\text { Creme Concentrado Anti-Idade }\end{array}$ & 50 & 89,67 & 3_caro & $\begin{array}{l}\text { Esthederm Intensive Retinol Creme é um creme, que ajuda a } \\
\text { nutrir, regenerar e fortalecer a pele, enquanto combate os } \\
\text { principais sinais de envelhecimento. Nutre profundamente e } \\
\text { proporciona uma sensação de conforto. Acelera a regeneração } \\
\text { celular natural. Reforça a estrutura da epiderme. Estimula a } \\
\text { produção natural de colagénio. Dá firmeza e atenua as rugas } \\
\text { profundas e marcas. Refina e uniformiza a tez. Devolve à pele } \\
\text { a sua luminosidade natural. Ideal para pele madura e } \\
\text { envelhecida. }\end{array}$ \\
\hline 92 & $\begin{array}{c}\text { Shiseido Future Solution LX } \\
\text { Creme De Dia Protetor }\end{array}$ & 50 & 478,99 & 4_dispendioso & $\begin{array}{l}\text { Shiseido Future Solution LX Creme é um creme de dia que } \\
\text { ajuda a hidratar, proteger e minimizar os efeitos do } \\
\text { envelhecimento da pele. Potencializa a beleza e luminosidade } \\
\text { naturais, regenera e revitaliza a tez. Fórmula rica e luxuosa que } \\
\text { torna a rotina de cuidados de pele num ritual de beleza que } \\
\text { apela aos } 5 \text { sentidos. Protege dos efeitos nocivos dos raios UV } \\
\text { (FPS20), agentes poluentes e radicais livres, enquanto }\end{array}$ \\
\hline
\end{tabular}

${ }^{5}$ As descrições apresentadas estão conforme apresentadas na fonte (disponível em https://skin.pt/ e recolhida em agosto de 2020).

No 8-10/2021 | 26-39 | https://doi.org/10.26334/2183-9077/rapln8ano2021a3 


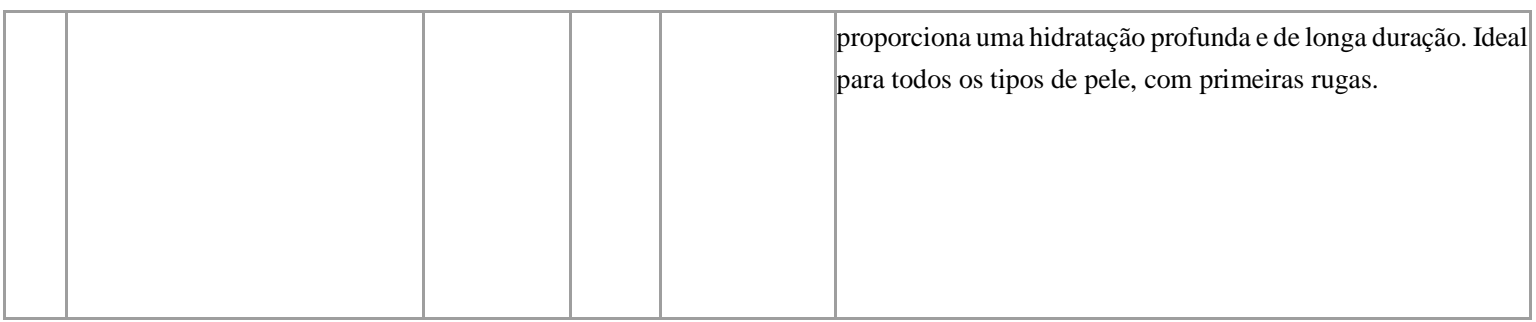

Figura 2. Exemplos extraídos da BD

Aquando da construção da BD, pareceu-nos importante categorizar os produtos relativamente à tipologia dos preços em quatro categorias, a saber: barato, acessível, caro, dispendioso ((i) produto barato (0-30€); produto acessível (31€-60€); produto caro (61€-90€); produto dispendioso (91€ -...)). Esta divisão deveu-se a uma premissa impressionista que previa a possibilidade de o preço do produto influenciar o vocabulário utilizado, visto ter como alvo públicos com características diferentes.

Na secção análise, apresentaremos uma breve reflexão acerca do texto descritivo que acompanha uma amostra da BD.

\section{Dados}

Na presente secção, apresentamos os dados extraídos através do programa Sketch Engine ${ }^{6}$, relativos a uma amostra de 112 textos, referentes a 112 produtos cosméticos, relacionados com o envelhecimento. Estes 112 textos foram divididos em quatro categorias relativamente ao preço: 28 textos para a tipologia barato, 28 textos para a tipologia acessível, 28 textos para a tipologia caro e 28 textos para a tipologia dispendioso.

\begin{tabular}{|l|c|c|c|c|c|c|c|}
\hline textos & formas & lemas & nome & verbo & adjetivo & advérbio & outros \\
\hline 112 & 8992 & 679 & 297 & 156 & 143 & 36 & 47 \\
\hline
\end{tabular}

Figura 3. Características do corpus consoante a tipologia do preço do produto

Na figura 3, verificamos que quanto aos 112 textos, este é um corpus de pequena dimensão, com 8992 formas, que correspondem a 679 lemas, dos quais 341 surgem apenas uma vez no corpus (formas hápax). Verificamos, globalmente, que os 679 lemas quanto à categoria gramatical se distribuem 297 (44\%) na categoria nominal; $156(23 \%)$ na categorial verbal; $143(21 \%)$ na categoria adjetival; $36(5 \%)$ na categoria adverbial e 47 lemas $(7 \%)$ na categoria das palavras gramaticais.

Relembrando que uma das nossas premissas previa a possibilidade de o preço do produto influenciar o vocabulário utilizado, visto ter como alvo públicos com características diferentes, apresentamos a Figura 4.

\begin{tabular}{|l|c|c|c|c|c|c|c|}
\hline tipologia & lemas & hápax & nome & verbo & adjetivo & advérbio & outros \\
\hline barato & 376 & 179 & 160 & 88 & 75 & 20 & 33 \\
\hline acessivel & 401 & 179 & 175 & 94 & 77 & 21 & 34 \\
\hline caro & 309 & 112 & 116 & 85 & 59 & 16 & 33 \\
\hline dispendioso & 302 & 97 & 114 & 81 & 59 & 17 & 31 \\
\hline
\end{tabular}

Figura 4. Distribuição dos lemas do corpus consoante a tipologia do preço e a categoria gramatical

\footnotetext{
${ }^{6} \mathrm{https}: / / \mathrm{www}$. sketchengine.eu/
} 
Os 112 textos apresentam, sensivelmente, o mesmo número de lemas (uma diferença pouco significativa de 99 lemas entre o grupo acessível e o grupo dispendioso). O grupo acessível apresenta um maior número de diversidade de lemas que os restantes grupos e o grupo caro o menor número. Relativamente à distribuição gramatical, verificamos que há preferência pelo uso de nomes seguido de verbos e de adjetivos. Sobre as unidades usadas apenas uma vez em cada grupo, observamos que apenas o grupo dispendioso se destaca com o valor mais baixo de unidades hápax.

Os dados recolhidos e apresentados acima podem indicar que as estratégias de comunicação entre as categorias poderão ser ligeiramente diferentes, em particular quando observados os números.

Para compreender melhor os dados, fizemos uma Projeção Factorial de todas as unidades usadas usando o Lexico $^{7}$, como se observa na Figura 5.

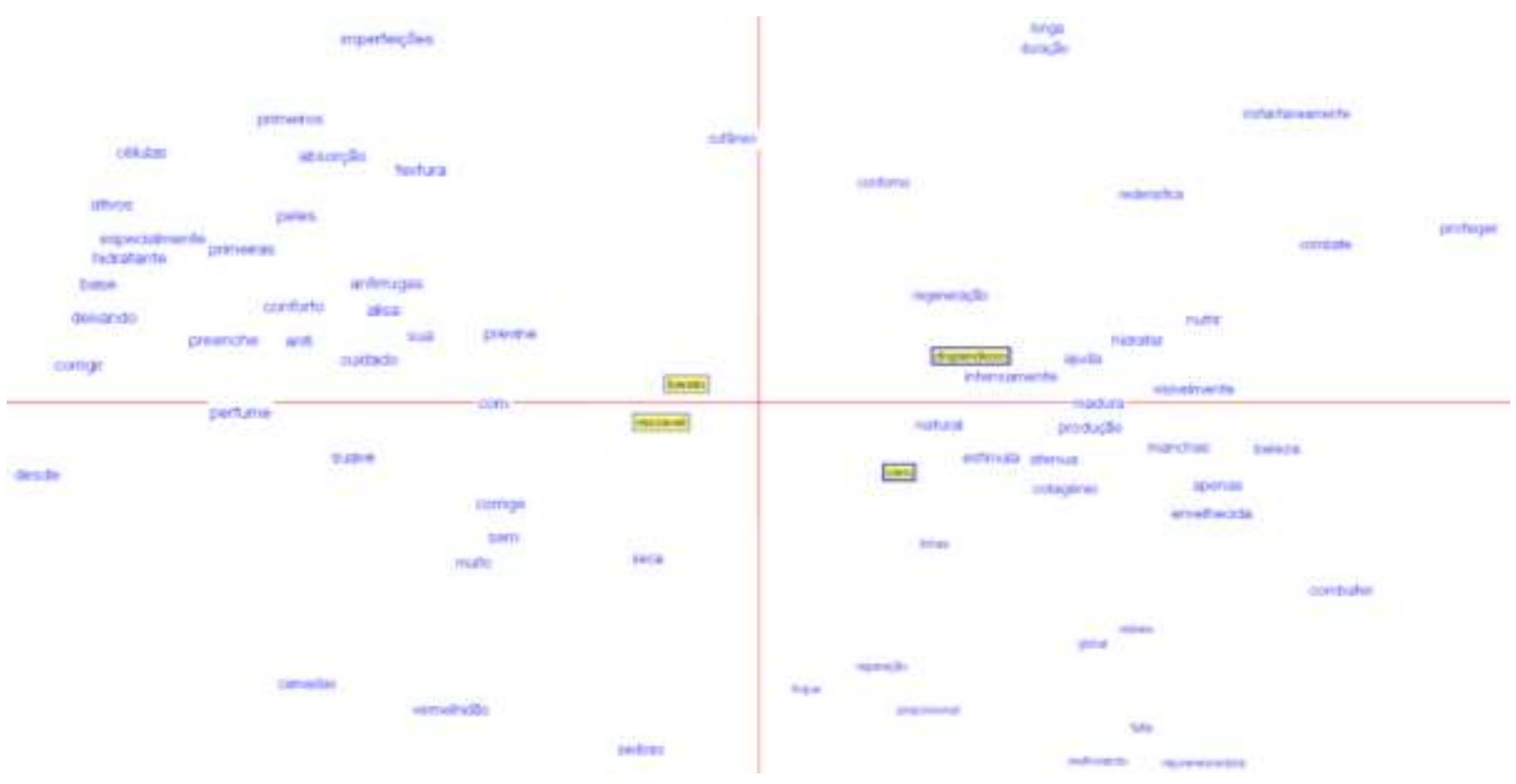

Figura 5. Projeção factorial das unidades lexicais de todos os textos.

A Figura 5 deve ser lida da seguinte forma:

(i) no centro do gráfico, na junção dos dois eixos, é possível observar o léxico neutro e partilhado por todos os grupos, como, por exemplo, as palavras gramaticais (que, por uma questão de clareza de imagem, foi apagada).

(ii) nas margens do gráfico, situa-se o léxico específico e pouco comum. Por exemplo, as unidades lexicais "imperfeições" e "células" são exclusivas do grupo barato.

(iii) o léxico que surge entre dois grupos indica proximidade lexical. Por exemplo, entre os grupos dispendioso e caro, as unidades "madura", "produção", "visivelmente" são partilhadas. Outro caso semelhante é o da unidade "cutâneo", situada entre os grupos barato e dispendioso.

\footnotetext{
${ }^{7}$ Software gratuito Lexico 5.8.1 desenvolvido pela equipa de André Salem do SYLED-CLA2T, http://www.tal.univ-paris3.fr/lexico/
} 
Assim, após analisar a imagem acima, é possível compreender a forma como as unidades lexicais se posicionam, tendo em conta a frequência e a distribuição, nos quatros grupos. Concluímos que há uma evidente proximidade entre os grupos barato e acessível por um lado e caro e dispendioso por outro.

\section{Análise Discursiva}

Na presente secção, apresentaremos uma análise de textos descritivos de produtos antienvelhecimento e, não obstante convocarmos dados relativos a outros textos da $\mathrm{BD}$, centraremos a análise, essencialmente, numa amostra de três exemplares, inserindo-se, cada um, numa categoria de preço diferente - barato, acessível, dispendioso. $\mathrm{Na}$ análise, tendo em conta os contributos acima apresentados, focar-nos-emos nas noções de ethos, face, FTA e implícito conversacional.

\begin{tabular}{|c|c|c|c|c|c|}
\hline$N^{o}$ & produto & capacidade & preço & tipologia & descrição \\
\hline 13 & $\begin{array}{c}\text { Nivea Cellular Anti-Age } \\
\text { Creme de Noite }\end{array}$ & 50 & 17,75 & 1_barato & $\begin{array}{l}\text { é um creme hidratante que ajuda a atenuar as rugas, aumentar a } \\
\text { firmeza e melhorar a renovação celular durante a noite. Hidrata } \\
\text { intensivamente e acelera a regeneração cutânea natural. } \\
\text { Redensifica profundamente e aumenta a firmeza da pele. Ideal para } \\
\text { todo o tipo de pele. }\end{array}$ \\
\hline 57 & Apivita Bee Creme Noite & 50 & 60,00 & 2_acessível & $\begin{array}{l}\text { é um creme rico que repara e atenua os principais sinais de } \\
\text { envelhecimento do rosto durante a noite. Corrige os principais } \\
\text { sinais de envelhecimento da pele. Nutre e estimula a reparação, } \\
\text { hidratação e defesas naturais da pele. Atenua as linhas e rugas, } \\
\text { enquanto ilumina intensamente a tez. Reduz as manchas e } \\
\text { vermelhidão para uma tez mais uniforme. De ação revitalizante e } \\
\text { energizante. Reestrutura e define os contornos do rosto. } \\
\text { Proporciona proteção contra as agressões externas diárias. Ideal } \\
\text { para a pele seca, madura e envelhecida. }\end{array}$ \\
\hline 21 & $\begin{array}{l}\text { Valmont Hydra3 } \\
\text { Regenetic Creme }\end{array}$ & 50 & 191,36 & 3_dispendioso & $\begin{array}{l}\text { é um creme de rosto com uma fórmula muito rica que ajuda a } \\
\text { hidratar intensamente, enquanto combate os principais sinais de } \\
\text { envelhecimento. Hidrata profundamente e de forma prolongada. } \\
\text { Atinge } 3 \text { níveis de profundidade cutânea: o estrato córneo, a } \\
\text { epiderme e derme. Combate o envelhecimento de pele associado à } \\
\text { desidratação. Reativa o processo de hidratação cutânea natural. } \\
\text { Cria um filme protetor e nutritivo para uma sensação de conforto e } \\
\text { suavidade de longa duração. Ideal para todo o tipo de pele } \\
\text { desidratada. }\end{array}$ \\
\hline
\end{tabular}

Figura 6. Exemplos de textos de produtos.

\subsection{Nome do produto}

Comecemos, então, por observar as estratégias léxico-semânticas manipuladas na construção do nome do produto.

(1) Nivea Cellular Anti-Age Creme de Noite

(2) Apivita Bee Creme Noite

(3) Valmont Hydra3 Regenetic Creme 
Ao observar os exemplos acima, verificamos existir uma menção explícita da marca, como Nivea, Apivita, Valmont, nos três casos. Tendencialmente parece ser comum a preferência das marcas pela manutenção da língua de origem (francês e inglês predominantemente) e, em alguns casos, a coexistência de apenas algumas unidades lexicais em português, como é o caso de creme de dia/noite/rico. Há também a preferência por usar estrangeirismos para nomear alguns compostos ou os princípios ativos (retinol), bem como algumas funções do produto (correct, renew, anti-age, regenetic).

A partir da análise realizada, colocamos a hipótese de que o público não exige a tradução destas estruturas, pelo menos no mercado nacional, o que nos conduz a várias questões: será que as marcas acham que o consumidor domina línguas? Ou apenas apostam na tradução do texto descritivo, por questões de branding. mantendo sem alteração a denominação do produto em qualquer território onde o vendam?

Partindo de uma breve pesquisa, pudemos constatar que os mesmos produtos publicitados em França ou Espanha são apresentados com a mesma estratégia, ou seja, o nome do produto na língua original e a descrição traduzida para a língua do público-alvo.

\subsection{Descrição do produto}

Concentrando a atenção no texto da descrição, verificamos que o mesmo tem como função explicar ao consumidor para que serve, onde se deve aplicar, como saber se este produto é o adequado e para que tipos de pele é mais indicado. Verifiquemos, abaixo, com maior pormenor, algumas das estratégias linguísticas manipuladas.

\subsubsection{Função do produto}

A partir de uma observação mais detalhada da descrição do produto, é possível concluir que a sua função principal é a informação que surge em primeiro lugar. Assim, na amostra recolhida, a função apresentada para todos os produtos é hidratar, ser hidratante, ser rico em (ter na composição química algo que permite) hidratação. É curioso, no entanto, verificar que, tratando-se de um produto antienvelhecimento, a primeira informação fornecida seja a de hidratação - característica que, à partida, qualquer creme possuirá. Neste sentido, começamos por acreditar que as marcas, ao produzirem o seu discurso publicitário, procuram proteger-se, não se comprometendo com efeitos miraculosos.

De destacar, igualmente, o facto de os textos mencionarem a zona do corpo a que se destina a posologia, neste caso, a pele do rosto, da tez. Na verdade, o consumidor podia subentender que um creme é para uma zona do corpo, mas o que verificamos é que a estratégia utilizada pelas marcas é mencionar explicitamente que se trata de um produto para hidratar a pele, no caso de esta apresentar um conjunto de características, tais como, os primeiros sinais de envelhecimento ou os principais sinais de envelhecimento. A formulação apresentada, uma vez mais, parece corroborar a hipótese do pouco compromisso assumido pela marca, uma vez que a não explicitação de quais os sinais de envelhecimento, em concreto, potencia uma ampliação do público-alvo - será a pele seca um sinal de envelhecimento? Serão somente as rugas? As linhas de expressão? E quais são as rugas e as linhas de expressão que traduzem o envelhecimento? A partir de que idade é considerado um sinal de envelhecimento?

Ao observar a amostra, uma vez mais, verificamos que o discurso se dirige à pele da pessoa e não à própria pessoa. Cremos tratar-se de uma estratégia de proteção da face, evitando um FTA, cujo implícito, naturalmente, será o de que todas as características apontadas à pele sê-lo-ão referentes à pessoa, mas de forma mitigada. As diferentes marcas referem que o creme se destina a pele desidratada, a pele que apresenta sinais de envelhecimento, entre outros, ou seja, a pele da pessoa é o alvo do creme e não a pessoa. 
Por fim, outra estratégia que verificamos na nossa amostra foi a menção sistemática de uma frase como "Ideal para todo o tipo de pele", "Ideal para a pele seca, madura e envelhecida" ou "Ideal para todo o tipo de pele desidratada". Com esta descrição final, qualquer consumidor consegue identificar-se, dado que é mais fácil o consumidor entender o que significa desidratado e englobar todos os tipos de pele na sua descrição, o que potencia a abrangência de um conjunto maior de futuros consumidores. Podemos refletir ainda sobre a situação relativa à facilidade com que a pele humana tem tendência para desidratar, o que revela que, ao usar este tipo de menção, a mensagem é de promessa de hidratação e não mais do que isso.

\subsubsection{Ação do produto}

No presente trabalho, optamos por distinguir aquilo que é a função do produto, ou seja, a característica que é apresentada em primeiro lugar na descrição do mesmo, e a sua ação, i.e., a descrição do seu alcance.

No presente ponto, debruçar-nos-emos, então, sobre a ação do produto.

Ao analisarmos a totalidade de textos recolhidos na nossa BD, contabilizamos um total de 156 verbos, sendo os 20 mais frequentes os que a seguir se apresenta na Figura 7.

\begin{tabular}{|c|l|c|}
\hline $\boldsymbol{N .}^{\boldsymbol{o}}$ & \multicolumn{1}{|c|}{ verbo } & freq. \\
\hline 1 & ser & 120 \\
\hline 2 & hidratar & 90 \\
\hline 3 & proporcionar & 60 \\
\hline 4 & atenuar & 56 \\
\hline 5 & nutrir & 56 \\
\hline 6 & estimular & 54 \\
\hline 7 & proteger & 50 \\
\hline 8 & ajudar & 44 \\
\hline 9 & corrigir & 40 \\
\hline 10 & prevenir & 38 \\
\hline
\end{tabular}

\begin{tabular}{|c|l|c|}
\hline $\boldsymbol{N .}^{\boldsymbol{o}}$ & \multicolumn{1}{|c|}{ verbo } & freq. \\
\hline 11 & alisar & 32 \\
\hline 12 & melhorar & 29 \\
\hline 13 & combater & 28 \\
\hline 14 & preencher & 26 \\
\hline 15 & revitalizar & 25 \\
\hline 16 & suavizar & 23 \\
\hline 17 & aumentar & 23 \\
\hline 18 & iluminar & 23 \\
\hline 19 & reduzir & 22 \\
\hline 20 & regenerar & 21 \\
\hline
\end{tabular}

Figura 7. Listagem dos verbos mais frequentes na BD (com mais de 20 ocorrências).

Facilmente se percebe que, excetuando os verbos ser e hidratar, existe uma panóplia de verbos que parecem não comprometer as marcas.

Verbos como ajudar, atenuar, estimular representam um tipo de modalização velada, na medida em que a marca não se compromete com o produto final, mas, sim, com um progresso (dependente da evolução natural e do ponto de partida). Reativar, na mesma linha, implica voltar a um estado anterior. "Reativar um processo natural" pode implicitar que, se o processo natural estiver comprometido, o produto não pode operar qualquer milagre.

Vejamos os exemplos abaixo ${ }^{8}$.

(4) Nivea Cellular Anti-Age Creme de Noite: "é um creme hidratante que ajuda a atenuar as rugas, aumentar a firmeza e melhorar a renovação celular durante a noite. Hidrata intensivamente e acelera a regeneração cutânea natural. Redensifica profundamente e aumenta a firmeza da pele. Ideal para todo o tipo de pele"

\footnotetext{
${ }^{8}$ Negritos nossos.
} 
No exemplo (4), verificamos que a descrição do produto promete “ajudar a atenuar”, o que, por si só, é uma promessa sem grande ambição. Na verdade, a marca não se compromete com um resultado final, nem com uma solução efetiva do problema. Ademais, a descrição parece ir ao encontro do que acima já tinha sido exposto: verbos como "melhorar" ou qualquer outro que seja antecedido por um prefixo "re-" implicitam a ideia de dependência do ponto de partida. Algo como: se a sua pele era X, talvez consigamos regressar a X. Mas se a sua pele era Y, o creme não operará qualquer milagre.

Outro aspeto interessante a destacar na análise diz respeito ao facto de os autores da descrição se focarem muito na ideia de "natural". Quando, no texto, a marca opta pela expressão "acelera a regeneração cutânea natural", não há qualquer compromisso com um resultado concreto, na medida em que a regeneração natural de cada pele tem ritmos diferentes. Se não for natural, para determinada pele, fazer uma regeneração rápida ou eficaz, não podemos afirmar que a ação do produto tenha falhado, na medida em que apenas se compromete em reforçar aquilo que já aconteceria naturalmente.

Vejamos, em seguida, mais exemplos.

(5) Apivita Bee Creme Noite: "é um creme rico que repara e atenua os principais sinais de envelhecimento do rosto durante a noite. Corrige os principais sinais de envelhecimento da pele. Nutre e estimula a reparação, hidratação e defesas naturais da pele. Atenua as linhas e rugas, enquanto ilumina intensamente a tez. Reduz as manchas e vermelhidão para uma tez mais uniforme. De ação revitalizante e energizante. Reestrutura e define os contornos do rosto. Proporciona proteção contra as agressões externas diárias. Ideal para a pele seca, madura e envelhecida."

No exemplo (5), uma vez mais, constatamos a existência de promessas vagas, opacas que, bem analisadas, não nos permitem afirmar que a marca se esteja a comprometer com um efeito concreto. Ao utilizar expressões como "os principais sinais de envelhecimento", sem especificar do que se trata, o consumidor fica sem saber, em concreto, o que esperar do produto em causa. Conforme já havíamos questionado acima: o que são os principais sinais de envelhecimento?

Também neste caso, à semelhança do exemplo anterior, parece existir uma tendência para o recurso àquilo que é o processo natural de cada pessoa, ilibando a marca de qualquer responsabilidade. Assim, quando é referido que "nutre e estimula a reparação, hidratação e defesas naturais da pele", a marca parece, simplesmente, desresponsabilizar-se, através de um discurso vago, opaco e altamente dependente das características naturais de cada pessoa.

Por fim, reparamos na existência do termo "atenua", desta vez associado a dados mais concretos, como "as linhas e as rugas". De facto, e contrariamente ao que possa parecer numa primeira abordagem, o verbo atenuar compromete, também ele, muito pouco a marca. Como poderia o consumidor provar que não houve qualquer atenuação? Até que ponto o próprio consumidor não acreditará numa atenuação, mesmo que ela não se verifique?

Uma vez mais, a opacidade das expressões iliba a marca de quaisquer responsabilidades.

(6) Valmont Hydra3 Regenetic Creme: “é um creme de rosto com uma fórmula muito rica que ajuda a hidratar intensamente, enquanto combate os principais sinais de envelhecimento. Hidrata profundamente e de forma prolongada. Atinge 3 níveis de profundidade cutânea: o estrato córneo, a epiderme e derme. Combate o envelhecimento de pele associado à desidratação. Reativa o processo de hidratação cutânea natural. Cria um filme protetor e nutritivo para uma sensação de conforto e suavidade de longa duração. Ideal para todo o tipo de pele desidratada.' 
No exemplo (6), uma vez mais se verifica que a marca recorre a estratégias de atenuação que permitem uma diminuição do compromisso com os efeitos do produto. Vejamos, por exemplo, a expressão "que ajuda a hidratar" ou mesmo "combate os principais sinais de envelhecimento". De novo, se pergunta: quais são os principais sinais de envelhecimento? E os sinais de envelhecimento secundários?

No presente exemplo, a marca tende a comprometer-se, apenas, com as consequências de uma boa hidratação, deixando essa promessa explícita, ao longo de todo o texto. Vejamos: "hidrata profundamente", "combate o envelhecimento de pele associado à desidratação", "reativa o processo de hidratação". Curiosamente, estamos perante um exemplar de uma das gamas mais caras, o que causa alguma surpresa a potenciais consumidores, como nós. Afinal, que público é aquele que paga mais por menos promessas?

Observamos, igualmente, nestes e noutros textos constantes na nossa BD, que, em diversas passagens, surgem sequências verbais (conjunto de dois ou mais verbos imediatamente seguidos ou interpolados com informação), como em “reparar e proteger" ou "ajudar, nutrir, proteger, redensificar, rejuvenescer". Também esta opção não parece inocente, na medida em que, para alguns consumidores, mais será sempre sinal de melhor. O excesso de informação, por outro lado, também permite distrair o leitor e transmitir-lhe uma sensação de completude que, analisada ao pormenor, representa um grau de compromisso quase nulo. Vejamos, abaixo, alguns exemplos de conjugação de diferentes verbos, numa mesma sequência.

A título de exemplo apresentamos o verbo hidratar, o mais produtivo, com pelo menos 16 sequências verbais possíveis, na Figura 8.

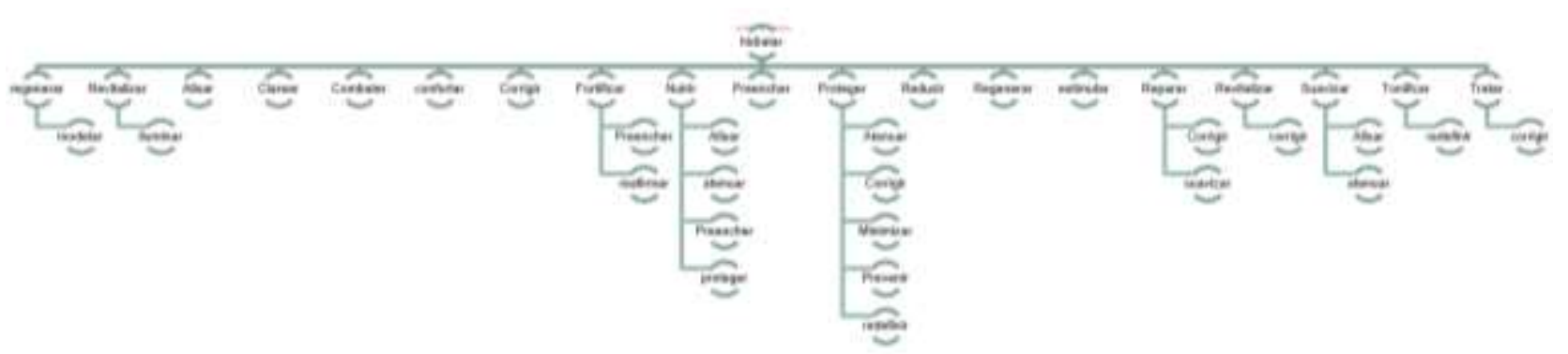

Figura 8. Verbo hidratar e respetivas sequências verbais

Mas, afinal, que consumidor é este? Que ethos adota? A necessidade de aquisição do produto surge porque contacta com o mesmo ou porque identifica, em si, características das quais não gosta? Será um consumidor crédulo? Um consumidor que, desde que não seja atacado diretamente, mas de forma mitigada, através de alusões à tez ou à pele, se sente envolvido pela mensagem que se pretende transmitir?

\section{Considerações finais}

No presente estudo, de caráter exploratório, pretendemos compreender como é que a indústria cosmética comunica a ideia de envelhecimento.

Verificamos, a partir da análise encetada, que:

(i) a descrição dos produtos se refere ao envelhecimento da pele e não da pessoa que possui essa pele, como forma de proteção da face do consumidor e, assim, mantendo uma relação cordial com este seu coenunciador (Adam \& Bonhomme, 1997). O envelhecimento é, assim, encarado como o resultado de um processo que a pele sofreu, algo externo às características internas e permanentes do consumidor. 
O milagre da juventude: uma análise linguística de exemplares de discurso publicitário da indústria antienvelhecimento

(ii) as características negativas são atribuídas explicitamente à pele e são apresentadas como resultado de um processo e não como característica inata.

(iii) para reverter este processo natural, as soluções apresentadas não representam qualquer compromisso por parte da marca, recorrendo a verbos que permitem modalizar as promessas (ajudar a redensificar e regenerar se tiver propensão para isso, ...).

(iv) os verbos mais utilizados remetem para a reversão do processo, a estimulação/reativação de uma tendência natural ou o melhoramento de algumas características (sem alusão ao efeito final esperado).

Relativamente às estratégias discursivas e escolhas lexicais, foi possível verificar que:

(i) o nome do produto posiciona o consumidor perante a marca e nem sempre é autoexplicativo (o uso de estrangeirismos pode dificultar a leitura imediata).

(ii) a função do produto é pouco esclarecedora, indica que é um creme de dia/noite ou rico em hidratação, mas não se compromete com muito mais do que isso.

(iii) o maior grau de compromisso é apresentado relativamente à função de hidratação, que parece ser a mais "fácil" de atingir, ainda que, neste sentido, não se distinga da função de outros produtos cosméticos da mesma natureza.

Relativamente à diversidade lexical, apesar de muito próximos os números, sobressai o grupo acessível com maior diversidade e o dispendioso com menor. Tal facto pode ser explicado porque o grupo do dispendioso já tem o seu público pelo preço e pela exclusividade que lhe dá acesso, i.e. quem compra esta gama está fidelizado.

Cremos que a variedade lexical do grupo acessível possa ser explicada pela quantidade de oferta no mercado e pela consequente necessidade de cativar um público que poderá facilmente selecionar um produto de outra marca na mesma gama.

Por último, a sequência de verbos que surge em todos os grupos mostra a potencialidade de um só produto, levando a que o consumidor assuma um ethos de bom comprador/interessado numa boa escolha, uma vez que, inconscientemente, assume também um ethos de credulidade, que acredita estar a tomar a melhor decisão perante um maior número de informações - ainda que, como vimos, as mesmas sejam vagas e opacas.

Em suma, o presente estudo, numa perspetiva exploratória, permitiu mostrar que imagem que o consumidor tem de si mesmo é fundamental, especialmente quando sente - por contacto com o produto ou com o próprio espelho - que existe a necessidade de contrariar os sinais de envelhecimento. Possibilita concluir, igualmente, que o compromisso das marcas é subtil, fazendo recair sobre o consumidor a responsabilidade do bom uso do produto e da sua genética (natural).

Evidentemente, muitas outras questões poderiam ser mencionadas, tais como as diferentes perceções e comunicações do envelhecimento consoante a cultura onde nos posicionamos, o facto de começarem a surgir mais publicidades desta natureza dirigidas a um público masculino, ou que a preocupação com a imagem não é exclusiva do séc. XXI, mas o escopo do presente trabalho pretendeu, de alguma forma, ajudar o leitor a analisar as promessas feitas nestes produtos, destacando os implícitos, o nível de compromisso assumido e, acima de tudo, levantando questões sobre o ethos que o mesmo pretende assumir, entre o crédulo e o informado.

\section{Referências}

Adam, Jean-Michel \& Marc Bonhome (1997) L'Argumentation publicitaire: rhétorique de l'éloge et da la persuasion. Paris: Éditions Nathan. 
Amossy, Ruth (1999) Images de soi dans le discours. La construction de l'ethos. Lausanne: Delachaux et Niestlé.

Amossy, Ruth (2012) L'argumentation dans le discours. Paris: Armand Colin.

Bruckner, Pascal (1997) A tentação da inocência. Rio de Janeiro: Rocco.

Castro, Ana Lúcia (2004) Corpo, consumo e mídia. Escola Superior de Propaganda e Marketing. Comunicação, mídia e consumo. São Paulo, 1 (1), p. 17-32, maio 2004.

Cathelat, Bernard (2001) Publicité et societé. Paris: Petite Bibliothèque Payot.

Ducrot, Oswald ([1972]/ 1980) Dire et ne pas dire: principes de sémantique linguistique. Herman.

Fairclough, Norman (1995) Media Discourse. London: Arnold.

Fonseca, Joaquim (1992) Linguística e texto/discurso: teoria, descrição, aplicação. Lisboa: Instituto de Cultura e Língua Portuguesa.

Goffman, Erving (1967) Interaction ritual. Nova Iorque: Pantheon Books.

Goffman, Erving (1979) Forms of talk. Pennsylvania: University of Pennsylvania Press.

Grice, Paul (1975) Logic and conversation. In. P. Cole \& J.L. Morgan (Eds.), Syntax and Semantics (Vol. 3) Speech Acts. Academic Press, pp. 41-58.

Kerbrat-Orecchioni, Catherine (1980) De la subjectivité dans le langage: quelques-uns de ses lieux d'inscription. In. L'énonciation. De la subjectivité dans le langage. Paris: Armand Colin, pp. 70-83.

Kerbrat-Orecchioni, Catherine (1992) Les interactions verbales. T. I. Paris: A. Colin.

Kerbrat-Orecchioni, Catherine (2005) Le discours in interaction. Paris: Armand Colin.

Mauai, Ângelo Américo (2015) Elementos para uma análise linguística do discurso realizado em situação de entrevista: contributos para o seu estudo semântico-pragmático. Dissertação de Mestrado em Linguística Portuguesa, Universidade Aberta. Disponível em http://hdl.handle.net/10400.2/4394. Acedido a 6 de março de 2021.

Marques, Maria Aldina (2000) Funcionamento do discurso político parlamentar: a organização enunciativa no debate de interpelação ao governo. Tese de doutoramento, CEHUM/ Universidade do Minho.

Palacios, Ana (2004) Velhice, palavra quase proibida; terceira idade, expressão quase hegemônica: apontamentos sobre o conceito de mudança discursiva na publicidade contemporânea. Comunicação apresentada no XX Encontro da Associação Portuguesa de Linguística. Lisboa, outubro de 2004. Disponível em http://www.bocc.ubi.pt/pag/palacios-annamaria-velhice-palavra-proibida.pdf. Acessado em 18 dez. 2004.

Riou, Nicolas (1999) Pub fiction: société postmoderne et nouvelles tendances publicitaires. 6.ed. Paris: Éditions d' Organisation.

Soulages, Jean-Claude (1996) Discurso e Mensagens Publicitárias. In. Agostinho Dias Carneiro (Org.) $O$ Discurso da Mídia. Rio de Janeiro: Oficina do autor.

Vion, Robert (1992/2000) La communication verbale. Analyse des interactions. Hachette.

Volkoff, Vladimir (2004) A essencial intolerância do pensamento politicamente correto. Mídia sem máscara, 27 de abril de 2004. Disponível em http://www.midiasemmascara.org/artigo.php?sid=1930. Acessado em 18 ago. 2004.

Weirnick, Andrew (2000) Andrew Blaikie: ageing and popular culture. Canadian Journal of Sociology Online, jan-fev 2000. Disponível em: http:// www.arts.ualberta.ca/cjscopy/ reviews/ageing.html. Acessado em 17 jan. 2004. 